\title{
- Surveillance \& society \\ Article $\quad$ Work and Play at the Threshold of Legibility: Theatre as Method and Pedagogy in Surveillance Research
}

\section{David J. Phillips}

Faculty of Information, University of Toronto, Canada.

davidj.phillips@utoronto.ca

\begin{abstract}
In May 2013, seven collaborators produced "Work and Play at the Threshold of Visibility." The intent of this collaboration was to use the skills of performers and the craft of theatre to explore poorly understood aspects of life within the modern apparatus of actuarial surveillance. This article describes and evaluates that project, situating it within surveillance theory, artistic explorations of surveillance, and performance methodology. We reach ambivalent conclusions regarding its success as research. Three suggestions are made to improve its method: more time to engage collaborative conflict, the inclusion of statistical expertise in the research team, and a more careful and focused recursive design of the research questions and the structure of the theatrical play. We also review the difficulties of making this project legible within the discourse of surveillance research, finding that while this article makes it legible as an exploration and critique of method, that contortion to institutional legibility has wrung the ineffable joy and fun from the event. We believe that that fun was in some way integral to the project, to its creative power, and to its value to the community of surveillance scholarship. We invite discussion of how that joy might be circulated within the discourse of surveillance theory.
\end{abstract}

\section{Introduction}

In May 2013, six collaborators and I produced and presented "Work and Play at the Threshold of Visibility." For my part, the intent of this collaboration was to use the skills of performers and the craft of theatre to explore poorly understood aspects of life within the modern surveillance apparatus. As such, it was research - an attempt to build theory in the field of Surveillance Studies. ${ }^{1}$

This article describes and evaluates that project. It is organized in six sections. Section 1 describes the intellectual landscape the project explored. Section 2 situates the project among recent forays into artistic engagements with surveillance. Section 3 situates it within the context of theatre and performance art as research methods. Section 4 describes the methodological genesis and intent of the project. Section 5 describes the piece as performed. The article concludes with a consideration of the success of the project, with respect to the creators' original intent, to unintended outcomes, and to the institutionalization of research.

\section{The Research Questions}

\footnotetext{
1 I will emphasize now, and elaborate later, that the research project itself was highly collaborative. While I was its primary instigator, and am now its chronicler and critic, the intellectual work of the piece came from all of us.

Phillips, D.J. 2015. "Work and Play at the Threshold of Legibility": Theatre as Method and Pedagogy in Surveillance Research. Surveillance \& Society 13(1): 57-77. http://www.surveillance-and-society.org | ISSN: 1477-7487

(C) The author(s), 2015 | Licensed to the Surveillance Studies Network under a Creative Commons Attribution Non-Commercial No Derivatives license.
} 
My own engagement with Surveillance Studies explores surveillance, spatiality, and identity, especially queer identity. Following Goffman (1959), I approach identity as the sharing, creating, and performing of socially meaningful relationships. Identity mediates between the individual and the social; it is the product of exterior relations and of interior subjectivity. It is concerned both with "positionality in the socialstructural system of social category relations based on power, exchange, distribution of resources, [etc.] and the habitus of embodied dispositions to action of particular meaningful kinds..." (Lemke 2008: 21). Identity is performed and performative; it is not fore-given but is continually brought into being, straining or reinforcing the structures that are both medium and outcome of the performance (Goffman 1959; Giddens 1984; Butler 1998; Phillips 2011a). By queer identity performance, I refer to self-conscious performances that acknowledge and point to the stakes of the performance, its constructed nature, and the techniques of its production (Butler 1998). I'm very interested in how surveillance infrastructures mediate queer identity performance (Phillips 2005, 2009).

I also consider the spatiality of surveillance. We might imagine three modes of surveillant interaction in the play of identity negotiation. These are face to face, visual, and actuarial. Goffman's seminal work (1959) concerns identity negotiation in the face to face mode. By "visual surveillance" I refer to the differential unbounding of space through enhanced or extended visuality or cognitive awareness. "Visual surveillance" refers to the troubling reconfigurations of presence and place mediated through CCTV, cellphone cameras, webcams, and online social media like Facebook. All of these practices both trouble and reinforce the norms and tropes of identity performance as distinctions between public and private, work personae and play personae are redrawn (Grimmelmann 2009).

But a perhaps more profoundly disturbing mode of surveillant interaction is that of "actuarial surveillance" - the systematic, statistical, analytic, algorithmic production of normativity. In its idealized form, actuarial surveillance individualizes each member of the population, and permits the observation and recording of each individual's activities, then collates these individual observations across the population. From these conglomerated observations, statistical norms are produced. These norms are then applied, directly or indirectly, back to the subjected individuals, who are categorized and perhaps acted upon according to their relation to the produced norm. Thus actuarial surveillance produces both discipline (that is, conformity to the norm), and the disciplines (regulated fields of knowledge and expertise) (Foucault 1977). It alters both the structures of visibility and the structures of meaning making. It renders us visible, it identifies us, in relation to the norms it produces. Actuarial surveillance as a technique of knowledge production and population management is becoming a central organizing principal of modern institutions. It is being adopted in more and more institutional settings, from insurance companies to marketers to police agencies. While some scholars refer to these practices as "dataveillance" (Clarke 1988), I use "actuarial surveillance" to resonate with the processes of statistical analysis and risk management, rather than just data collection (Phillips 2011a).

A dialectic of visual and actuarial surveillance is at work in the organization of online spaces, such as chat rooms and other social media. Operators of these spaces are often "Janus-faced," offering extended sensory presence to their users, while making actuarial sense of those users' activities, and selling that knowledge to advertisers (Campbell 2005; Steeves 2006). In practice, both online and off, sense making occurs both visually and statistically, and differently placed actors make different kinds of sense. And just as visual and actuarial surveillances are analytically distinct but practically entwined, so are data spaces and physical spaces enmeshed in complicated ways (Phillips 2011a).

Drawing on McGrath's claim that "space is the fundamental subjective condition of perception, of knowing and understanding the external world" (McGrath 2004: 10), I seek to explore the collision of the spaces of visual, actuarial, and face-to-face surveillance. What is going on, what is produced, what is destroyed, when the operators of social media platforms engage in actuarial surveillance of their subscribers, while those subscribers engage in visual surveillance of each other? What is at stake when the 
other-worldly connections of ChatRoulette are pinned on a Google Maps mashup (Phillips 2011b)? How can we take advantage of these ineffable, unmapped, unresolved fractures to critique and engage systems of surveillance "productively, creatively, [and] libidinally" (McGrath 2004: 209)?

\section{Surveillance Art and Theatre}

Before I was an academic, I had been a professional actor. I recently returned to that craft, and part of my sabbatical project was to try to find a way to bring theatre, pedagogy, and research into some kind of symbiosis. Many others have used the techniques of many artistic forms, including theatre, to engage surveillance. Many of these are chronicled in Ctrl[Space], a compendium of artistic engagements with "rhetorics of surveillance from Bentham to Big Brother" (Levin et al. 2002). In 2010, this journal published a special issue on "Surveillance, Performance, and New Media Art." John McGrath's Loving Big Brother (2004) offers perhaps the most extensive exploration of the ways in which artists are finding creative agency in surveillance space. Through new forms in the production of images, new patterns in their circulation, through transgressive interpretation, through an active and productive ambivalence toward visibility and presence, artists, as well as scholars, are straining hegemonic concepts of space, place, power and identity.

Yet without exception, the art described in these reviews concerns visual surveillance, and play with cameras. I wish to extend this troubling to the space of actuarial surveillance. Just as the art of visual surveillance can trouble the hegemonic ideology of Newtonian space, so the art of critical actuarial surveillance must trouble the ideology of data space. That is, it must approach surveillance practice not as a representation of entities, but as a production of entities, selves, and subject positions. It must help us understand and employ data as performative utterance - as presentation rather than representation.

Some recent work does just that. Blast Theory's work conflates and integrates data space and physical space in seriously playful games of affect, memory and trust. Super Vision, a 2005 production by The Builders Association imagined data bodies colliding with and enabling physical bodies as, for example, one person's unsullied records are used by another to create a credit-worthy self, or a traveler is pursued by his frequent flyer data (McGrath 2012). Eric Gradman has produced CloudMirror. In this piece, a camera and monitor reflect a conference-goer's image back to herself. But the camera also reads the visitor's identifier from her conference badge and uses that information to find her tweets and Facebook updates, which are superimposed in a thought bubble above her image in the monitor. ${ }^{2}$

But these works, while they engage actuarial surveillance, focus almost exclusively on the collection of data about individuals. Laurie Frick's work, in which she collects and visually represents her own biometric data, plays in the realm of pattern-finding and analysis. ${ }^{3}$ Yet few, if any, address the entirety of the surveillance process; the institutionalized, actuarial, statistical, population-based modes of analysis and meaning-making that inform organized responses to categorized individuals.

That is the unexplored territory I wished to venture into. I wanted to do it with theatre, and I wanted it to "count" as research.

\footnotetext{
2 http://www.blasttheory.co.uk/projects/can-you-see-me-now/, http://www.thebuildersassociation.org/prod supervision.html, http://www.gradman.com/cloudmirror

3 http://www.lauriefrick.com/
} 


\section{Theatre as Research}

Theatre as scholarly method was embraced first by ethnographers. Ethnographic theories recognized daily life as performance and as structured ritual. They also saw cultural expertise as embodied rather than discursive. Cultural knowledge could not simply be called up and expressed verbally by informants. Instead, it could be represented "only through action, enactment, or performance" (Fabian 1990: 6). Thus performance becomes "a method, as well as a subject of ethnographic research" (Fabian 1990: 86).

Theatrical techniques were embraced as a process of evoking the embodied understanding of others, of revealing the structures of everyday life, without doing violence to that understanding. In a performative epistemology, performance is an embodied, empathic way of knowing and "deeply sensing the other" (Conquergood 1985: 3). It "makes the invisible visible," illuminating power structures and forces that affirm the inherent, experienced, non-verbal knowledges of the actors involved. It gives presence and currency to theoretical engagements in a way that traditional paper-writing and conference discussion cannot (Hunter 2009: 232).

Performance ethnography is usually considered participant action research. It is reflexive and activist. It is intended to "create[...] opportunities for communion among participants, researchers and research audiences" and to "act[...] on the world in order to change it" (Conrad 2004: 16; Denzin 2003: 228).

Conquergood asserts that performance as research always plays along "three crisscrossing lines of activity and analysis." First, performance is a creative act. It is a work of imagination. Second, it is a pragmatics of inquiry, a mode of critique and reflection. Third, it is a tactic of intervention and citizenship (Conquergood 2002).

Performance can be used at various stages within the processes of ethnographic research. In the field, ethnographic technique may elicit embodied and innate knowledge through games and role play. By brainstorming, telling stories, enacting and re-enacting situations, looking for alternative scenarios, participant reflexive ethnographers can elicit and bring to consciousness the structures of power in their daily lives.

Through the 1970s, Augusto Boal developed a set of guided games to elicit and articulate embodied nonverbal knowledges, and to make them publicly available for contestation, intervention, and explorations of how-could-it-be-otherwise. First, an issue relevant to the players is identified, and through several days of gaming exercises, participants articulate their understanding and consciousness of that issue. The games are intended to both disrupt and recreate taken-for-granted social interactions and relations. Players are directed to write poems, make sounds, and create communal movement pieces, according to rules that mimic social regulation. However, the freedom to play both with and within those rules offers an incitement to creativity and alternate possibilities. These games workshops may then lead to performances, which are themselves open to intervention and re-writing by the audience (Boal 1985, 1992).

Performance techniques may be deployed at other stages and in other modes of ethnographic research. For example, the ethnographer may create scripts from interviews and field observations, and return those scripts to the participants for enactment and critique. Thus the scripts become a medium though which the participants can interpret, contest, and refashion the ethnographer's observations and analysis (Conrad 2004; Bagley 2008, 2009).

Arsem creates performance pieces that are not ethnographic, but that engage the audience in a structured way to communally think through engaging questions (Arsem 2009). She enacts her research by slowly, reflexively, and mutually elaborating both the issues she wishes to explore and the theatrical form in 
which to explore them. The performance process is both the medium and product of the research. For example, her Ada Project had its genesis when she became aware of two ancestors in $19^{\text {th }}$ century New England: one a medium and another a scientist testing other mediums' psychic abilities. She was piqued to explore a set of questions about spirits, science, women and the afterlife - about a historically situated, gendered, placed, classed position. She developed a piece in which participants are given historical texts and report to each other what they have read, questioning, in conditions of trust, belief in spirits, in science, and in the afterlife. Throughout this discussion, Arsem alters clothing, lighting, and the set to transform the performance environment and to provide a haptic experience of 19th century life.

However, neither performance art nor performance ethnography was quite what I was after. I was not trying to use theatrical techniques to make visible the embodied knowledge of my compatriots. Rather, I wanted to explore the implications of certain sets of hypothetical constraints and pressures.

I craved a release from rational argument, but I wanted to play with and within theoretically informed rules, relations, and scenarios. I wanted the research process to be communal and embodied. I intended to devise theatre in ways that engage randomness, embodiment, and theory to produce, extend, and critique theory. I wanted to use actors and improvisors as skilled and disciplined research tools.

The discipline of the actor or improvisor includes the embrace of and skill in:

- collaboration, communication, and collective modes of knowing;

- a focus on ever-shifting relationships rather than static entities;

- finding and elaborating conflict and tension;

- embodiment and the embrace of the tacit;

- the holding in abeyance of logic and abstraction;

- playing it as it lays-re-evaluating assumptions and reframing worlds to encompass phenomenon.

By engaging the practical consciousness and critical reflection of the performers (including the audience), by articulating through engagement rather than abstraction, focused, devised theatre can generate unpredicted insight. In this sense I wished to engage theatre as a method-like a survey, like an experiment - explicitly contrived with a focus and purpose, with a theoretical framework, and with a set of mechanisms for the creation of the as-yet-unknown.

\section{The Genesis of the Project}

I had twice tried, without success, theatrical research techniques to explore surveillance theory and to produce unexpected, credible insight. I tried first to adapt Tomasula's C-U SeeMe (2000/2001). This short story is structured as a complex and evocative set of vignettes of people looking at and revealing themselves to each other through various media for various reasons. I had hoped that by theatricalizing it, notions of space would become manifest. Because the story was written before the advent of social media, I also hoped to extend its reach by including such use among the characters. This was unsuccessful. It was a lonely process and too literal, too wordy, too much like writing a paper. I found that the characters merely parroted me, and not me at my best but me at my most polemic. Perhaps this was just another iteration of the perennial struggle with a stupid first draft, but it was disheartening, and not fun. ${ }^{4}$

I followed this with an attempt to knock myself off-kilter and to create a process that demanded that I approach surveillance situations in unfamiliar and uncomfortable ways. I developed scenarios by invoking

\footnotetext{
${ }^{4}$ For a recent, and remarkable, example of a scripted exploration of a set of themes around issues of visibility, revelation, and concealment, please see Caryl Churchill's Love and Information (2013).
} 
random processes. I used these random techniques first to create characters who were amalgams of theoretically informed proclivities and subject positions, then to set those characters in conflict. I drew cards to determine why each character wanted to be seen, why they wanted to watch, and how they liked to see and be seen (that is, in which space or mode of surveillance they were most at home). I then consulted the I Ching for the shape of the scene-the settings, motivations, events, and trajectories of the characters. My hope was that this would mobilize theoretical constructs in a formal but novel way and see them through conflict using the disciplines of playwriting. If the scene "worked," then a kind of validity would have been attained. However, I found the form too constraining. I found myself contorting credibility in my attempt to be faithful to the trajectories suggested by the I Ching. Although I abandoned this particular attempt at using this technique, I still found it full of rich possibility, and I intend to take it up again, perhaps as a framework for improvisation rather than playwriting.

At the time, though, I found myself frustrated at my attempts to negotiate originality within the constraints of my own frames of understanding and the form of the work. Fortuitously, I then met my primary collaborator, Michael Reinhart. An actor, performer, director, and dramaturg, he was also a doctoral student at my university, interested in my work on the performance of identity within surveillance infrastructures, but primarily in the structure of interdisciplinary collaboration and conversation. We met regularly to exchange expertise and eventually decided that creating a collaborative, devised theatre piece would be likely to satisfy each of us in our professional pursuits.

We first established a research question interesting to both of us and broad enough to allow eventual collaborators to narrow or redirect it. We settled on "What are the traps, the contradictions, the conflicts, the inevitabilities, the possibilities when life is organized around dataveillance?"

We assembled a team of collaborators, including a surveillance scholar/actor (myself), a polyglot dramaturg/director/performer (Michael), an actor (Neta Rice), a performance artist (Stephanie Berntson), a dancer (Elyse Waugh), a visual/projection artist (Monty Martin), a data wrangler (Justin Scherer), and a small audience. We tried but failed to find a critical statistician. All of these collaborators, with the exception of the audience and myself, were University of Toronto students, and paid as research assistants from a grant of which I was the principal investigator.

The collaboration began with four days of table work. We introduced ourselves over a collaborative dinner, each saying what they hoped to give to and get from the project. I distributed a small selection of articles and book chapters to read, mostly on surveillance, identity, and spatiality. In the course of discussing these readings, I gave an informal lecture on the particular model of actuarial surveillance that informs my work. I also suggested particular interesting understudied areas within that model, including questions such as:

- how are data made to mean?

- how are norms internalized?

- what are the avenues and pleasures of illegibility or unclassifiability, of outsider status, of the vagrant, of the queer?

Monty (our visual artist) and Justin (our data wrangler) each introduced the rest of the team to their expertise. Monty's was with Isadora, a software suite that allows the programmer to use many different streams of data to control permutations of many input streams of visual imagery. For example, an audiometer might measure the level of ambient sound. This sound level would determine the delay in the projection of a live image of a dancer. The dancer might then dance with that image of her prior self. As the audience applauded more loudly in appreciation, the projection of the prior self would be more and more delayed. The dancer's partner would slow and recede. 
Justin worked with networked sensors and Arduino programming. We hoped to develop a way to monitor some audience response and integrate that into the performance environment, making both the monitoring process and the process of data aggregation and sense-making visible and available for contestation. Throughout this period of table work, we all used whiteboards, large pieces of paper, colored pens, and sticky notes to generate and record interesting questions and avenues for exploration. We wondered how to engage the ground against which we are measured. We wondered how we might build an "aberrance monitor."

There followed ten days of rehearsal in a small theatre - a "de-frocked" church with dark brown walls, and a small stage and cyclorama behind a proscenium; washes of light articulated several areas of the central space; we and the audience had access to a basement shop, a storage room, and a balcony overlooking the main space.

We first tried to forge a way of working together in collaboration - engaging, sharing, and communicating across each of our modes of expertise. Michael asked us each to make a gift to the group of a solo; he also asked us to make a gift to the group of a disciplinary game, asking us to consider, in and with our bodies, how we train and regulate ourselves, and how we find that discipline useful or inhibiting. We warmed up together before every rehearsal.

We articulated themes and questions and scrawled them in chalk on the theatre walls, to the intense chagrin of the building administrators. We broke into small groups (sometimes very small groups-groups with one member) to further engage these questions. How could we prompt the audience to actively question the sense that we chose to make of the data we gleaned from them? How did we make these ideas that were flowing hot and heavy among us and make them theatre, make them fun? What was our central fiction?

We decided to concentrate on two themes - "Contortion into Legibility" and "Pleasures of the Outsider." The first theme was theoretically informed by the notion that surveillance infrastructures work, in part, because everyday life is structured to conform to the technical requirements of monitoring techniques. It was autobiographically informed by a recent medical procedure I had had for a neck pain. To diagnose the condition, to make it medically legible, the MRI technology (and the technician) required that I lay flat and still-exactly the position made impossible by the pain itself. The second was theoretically informed by ideas of contingent identities, and of the strategic refusal and problemetization of essential identity. How could we theatricalize the notion of the queer, the vagrant, the one without name or place, the one who eludes our categories?

We fixed a title: "Work and Play at the Threshold of Legibility." We fixed the structure of the performance. We set the lights, cleaned up specific acts and the transitions between them. We invited audiences of fifteen people for two consecutive performances.

\section{The Show}

The show was structured in five acts. The audience was admitted and enrolled; they were welcomed and oriented; they submitted to legibility tests; depending on the results of those tests, they were invited into spectacles designed "just for them." Finally, the cast offered them all a big finish blowout.

\section{Enrollment}

Elyse and I enrolled audience members as they entered, offering each a tag emblazoned with a unique hexidecimal guest ID and explaining that this guest ID would not be linked to their name. Thus, while we would be collecting information from each audience member throughout the evening, it would not be 
considered "personally identifying information" under current data protection laws. We would therefore be using it heedless of those laws.

\section{Welcome}

When the audience had been informed and enrolled, Neta addressed them en masse, welcoming them and introducing them to the joys of legibility - the history of categorizing and normalizing populations through information technologies, of measuring individuals against a grid (either a literal, visual grid, or a more abstract set of standardized measures), analyzing and categorizing the population (objectively and scientifically) according to the data thus produced. She invited the audience to be read and made knowable in a series of three legibility tests.

But before we could go on, we needed consent. An actor wheeled out a huge red "consent button," and Terms of Use scrolled frantically and illegibly on the cyclorama as Neta called in a confusing patter for one audience member to come up and give consent for the group.

\section{The Legibility Tests}

The tests were moments when the attendees attempted to contort themselves into legibility; to fit themselves to the grid, to meet the demands of the monitor. Attendees passed the test by becoming legible, by successfully being read by whatever monitor they are subject to. Further, they were read as a particular type, and depending on how they were read, they became eligible for different pleasures later.

Neta administered a psychographic test in which she gave each audience member a sequence of binary choices ("giraffe or zebra?" "title or author?" "dream or hallucination?"). Participants were not permitted to say "neither" but were warmly encouraged to offer a specific "other" choice. Monty used the Isadora suite to devise a "jitter monitor." The audience member stood before a camera, which projected their image on a large screen. Any movement would cause the image to fracture. The test would glean from the audience member data regarding whether, how often and for how long they remained successfully still. Stephanie administered a sarcasm test in which participants were asked to recite three phrases, like "That looks so good on you," first sincerely, then sarcastically. Their recitations were recorded and analyzed.

The administrators forwarded the gleaned data to Justin, our data wrangler and the representative of Justin Justin Dance Dance Data Brokers and Analytics International Limited (Canada). Throughout the performance, he sat in the middle of the main space, at a desk in a wash of white light, wearing a threepiece suit and Coke bottle glasses. He was a constant nexus, receiving raw data from the other performers and giving them processed data, arranging and sorting papers, making lists, and generally being busy.

Justin's first task was to decide, based on the data gleaned in the tests, how each attendee was to be typified, and which of three spectacles each attendee would be invited to.

\section{The Spectacles}

The spectacles were entertainments; they were gifts. They were designed to be fun, and to be themed around some sort of reference, however far-fetched, to issues of surveillance, tracking, monitoring, discipline, datafication, or sensemaking. Each was designed to make a distinction between, and to give different pleasures to, audience members who were insiders and those who were outsiders. Each was patrolled by a "policeman" who received from Justin a list of insiders. Insiders could actually engage in the spectacle; outsiders could only watch. However, the outsider may be able to see more of the operation of the spectacle than the insider could. Outsiders who wanted in were told that there may be myriad reasons why that would not be permitted: perhaps the content was illegal or restricted in their jurisdiction, perhaps they hadn't registered properly, perhaps their account had lapsed. In any event, they should contact their system administrator. 
In one spectacle, Elyse danced, tethered to a column, while Neta barked critical instructions at her. ("You're not pointing your toes. Tuck! Tuck! Tuck! You did this yesterday! Do it now! ...") Insiders were permitted to physically engage with Elyse; outsiders had to watch from the periphery. In Michael's spectacle, "The Blind Painter," he masked his eyes with painter's tape and tactilely explored his environment, returning, still blindfolded, to his canvas to paint what he had discovered. Insiders became part of the environment he explored, and saw the canvas he was painting. Outsiders saw his interaction with the environment, but not the painting. I developed a spectacle: "The Satisfaction of Shameful Desires," in which insiders would be permitted into a small viewing booth. There they would be offered a set of powerpoint slide shows chosen "specifically for them." These slide shows contained still images and videos of pleasures that verged on the fetishistic and grotesque-scary plane landings, show tunes, pastries, extreme opulence. Outsiders were denied entry, but could, if they were clever enough to find the monitor, see a video feed of the face of the insider watching the slide shows.

Before entering a spectacle, and after leaving, audience members were prompted to push a button that turned a timer on and off, allowing us to collect data regarding how much time each audience member spent in each spectacle. Of course, they were assured that this data was being collected so that we could improve their experience in later versions of the show.

\section{The Big Finish}

Finally, we made a show of collating all the data gleaned through the event, clustering the audience into three types, identifying the attendee who best epitomized the type, and offering that person a special gift carefully chosen to appeal to that type. We also called out and identified one audience member whom we were unable to classify, whom we could only describe as queer or vagrant or other. But we gave them a gift anyway: a slow dance with Michael. Finally, we offered a big finish designed to appeal to everyone. This was designed to illustrate the point that, though it was designed to please Everyman, that ideal Everyman does not exist. It is a figment of a restricted and somewhat boring cultural imagination, and geared to the least common denominator. And that denominator isn't even all that common. We offered all of the women in the cast performing the Macarena, up on the stage, with fabulous lighting.

\section{But was it Research?}

This project was intended to be research. It was intended as a foray into a (for me) new method, informed by theory, of exploring contemporary life. "The twin goals of 'method' are to create a research design where (1) you can be surprised by your findings and (2) others can be persuaded by them" (Luker 2010: 6). Given those standards, was this practice a successful "method"? Did we produce surprising, credible insights into important questions?

I'm first drawn to ponder exactly what it was that we produced whose novelty and credibility are to be determined. Where are the findings? In particular, are we to review the development process, the performance, or some archive that might be fashioned to fix and chronicle those events? Regardless of which of these we choose to interrogate, how do we consider whether its insights are credible or novel? Novel to whom? What standards of credibility ought to prevail?

These questions are endemic to arts-based research, and especially to performance-based research, since it is often considered necessarily ephemeral and transient, beyond the realm of fixed knowledge, unavailable for review. The questions rise perennially, too, in participatory action research. For whom is the research intended? In what community is its efficacy, reliability, or usefulness to be considered? By what metric do we determine its worth?

Let me first consider the rehearsal and production process and ask for whom it was creative, what was created, and whether that creation was useful. I must acknowledge that the research design put a very low 
priority on replicability, validity, or reliability. There was no metric built into the process, nor an a priori determination of a bar that we could reach to satisfy ourselves that findings had been found. This was embodied work. We were acting as artists, and I at least was being intentionally thoughtful but careless. We were all relying on our varied experience to know, often in a way beyond language, when something worked.

And for some of us, anyway, it certainly worked. Ideas came from one participant, were filtered through the experience and expertise of another, and were handed back, troubled and troubling. One of the collaborators, Neta, wrote afterward,

I began to see how we jump at every new piece of technology to help us see a complex, subjective world "objectively." It had never occurred to me how pervasive this idea of legibility is, the question of how we categorize and measure so that things/people/worlds make sense. It had never occurred to me that this - and not the invasion of privacy — was what surveillance was really about.

This kind of collaborative intellectual play reminded me very much of a seminar-albeit the best and most exciting seminar I've ever been part of.

But seminars are not considered research, and I, the Principal Investigator, had been very well aware of the intellectual domain whose discovery so excited Neta. If I have to be brutally honest with myself, I must admit that I was not and am not satisfied that we had really advanced inquiry into the questions that really intrigued me within Surveillance Studies. I neither think nor feel that we really troubled the questions that animate my research ("How are data made to mean?" "Where is queer pleasure and queer power?"). Putting aside, for a moment, the question of whether my sense of success or failure has any real bearing on the project's value as research, I'd like to explore how the method may have been improved.

There were at least three impediments to this project attaining the status of "research." The first was the simple lack of time. Under duress to produce a show, to have something "finished" in two weeks, we torqued the research process to fit the theory. Instead of allowing new concepts to emerge from the collaborative generation of scenes, scenarios, and events, we imposed dramatic form on good old standbys of surveillance theory. For example, we imposed rather than discovered the outsiders' pleasures in the spectacle. That is, we structured the spectacles so that the outsider could have a critical view, rather than an immersive experience. I'm not at all sure that this is really how surveillance positions the vagrant, the unclassifiable, the unknowable. But it seemed theoretically justifiable and we had to do something. With more time, with less pressure from the opening night curtain, we could have spent more time developing theoretically informed play, and allowed that play to reflexively inform the theory.

We fell back not only on established theory, but on established disciplinary power relations. I was able, as the professor, the Principal Investigator, the signer of the checks, and the oldest man in the room, to have my will. The title and the structure of the piece were negotiated among us all, but they were negotiated on my terms. Again, we were pushed - I pushed - to come up with a story, with a show, and quickly. And that push did not serve us well as researchers. I like to think that given more time, I would have welcomed more robust conflict.

The second impediment was that the team lacked a necessary element of domain knowledge of data capture, analysis, and visualization. We wanted to explore how data are given voice and made to speak by interested social actors within institutions using a certain set of economic, cultural, and technical resources. But we found it beyond our ability to actually work with real time data, so we made it all up to illustrate relations and phenomenon we had already theorized. All data gathering and analysis ended up as smoke-and-mirrors theatrics. We had originally intended to collect some kind of simple biometric in real 
time from each audience member. One thought was to place pressure sensitive resisters under the seat cushions, collect and display the data produced, then ask the audience to engage in arguments over its meaning. But we couldn't figure out how to set that up to reliably produce and deliver any kind of data to argue over. We then tried to set up timers at the entrance to each of the spectacles, measuring how long each audience member spent there. We could, perhaps, have produced and gathered that data in real time, but not nearly in time to do any kind of useful analysis. So we relied on cheap theatricks: we gave much show of gathering data, but the categories we produced, and the privileges we granted or denied on the basis of those categories, were determined beforehand and chosen for theatrical effect.

This was not a fatal flaw to the project's legitimacy. There was a great value in simply playing with, extrapolating on, and making ridiculous the quite familiar everyday categorizations were are all subject to. We were able set up moments to confuse, disorient, and re-orient the audience, but with more skill, we could perhaps have given the audience agency to intervene.

Having statistical expertise on the team would also have given us another source of creative friction. During the rehearsal process, the multidisciplinary composition of our team frequently offered a frisson of creative dissonance. As we explored in our own languages and through our own experiences of the processes of disciplining - of being read, judged, and corrected within imposed and extracted grammarswe engaged productive conceptual conflicts. Michael described his "Blind Painter" spectacle as an exploration of the idea that "all surveillance is haptic." I didn't know what he meant by that, and the rehearsals gave us an opportunity to negotiate that meaning and contextualize it within the piece as a whole. Monty pushed back continually on my expertise with his own sense of how surveillance workedof, for example, the aims and techniques of Google. And I pushed back to urge him to see that the difficulties he was having getting his equipment to "read" the movements of the dancers' bodies was exactly the issue we were seeking to explore. Speaking solely for my self, at this point in my surveillance research I would have loved to have that sort of conflict with someone who was really trained in data analytics.

Finally, I believe that the project would have fared better as surveillance research if it had been more carefully designed. Were I to do this again, I would try to engage a research team of improvisors and clowns, develop more precise research questions that addressed specific areas of tension and conflict, and develop the gaming structures to elicit and elaborate those tensions, perhaps using the I Ching technique mentioned earlier.

But (and I ask this quite seriously), who cares what I think? Knowledge is social. It is created and kept alive in discourse, and the touchstone of successful research is its circulation within academic discourse. It is not successful research, it is not a contribution to knowledge, unless it is adopted and circulated with the institutions that reify that knowledge. It is for the community of discourse that is Surveillance Studies, not for me, to be the arbiter of whether any questions within that domain have been troubled in this project.

But how, given the techniques and structure of the project, can it circulate and attain truth and legitimacy? How can the production process and the performance be described and transcribed in ways that can be circulated and latched upon? Is performance not necessarily ephemeral and transient? As Spatz points out, "ephemerality" and "transience" are contextually dependent. For theatre practitioners, every "ephemeral" performance, even improvisation, is the "an instance of a repeatable structure" (Spatz 2011: 52). The difficulty of fixity is not inherent in the event, but in the mechanisms and institutions of the circulating discourse. Were the Threshold of Legibility project to evolve into a set of games, or a set of procedures for developing games, it could feasibly circulate within text-based journals.

Performances are another matter. Spatz calls for an "archive of practice," specifically a multimedia archive, to become "the foundation for a community of embodied knowledge" (2011: 56). But this is a 
rather technocratic solution. While the idea of a multimedia archive may be attractive within some academic disciplines, particularly the arts and humanities, it is not at all clear to me that other disciplines would begin to engage theatrical, performative, embodied research if only they could see it. And if we are to take seriously the notion that research can occur in performances to which the audience contributes with each iteration, how can that research circulate within the academy?

As it is, I have to offer neither a replicable template for a show, nor a recording of any instance of that show. Instead, to gain purchase within the discourse of Surveillance Studies, I have this article, targeted for a special issue themed on alternative methodologies and epistemologies for theorizing surveillance in everyday life. And while the work of contorting those now long past few weeks of theatre into a form legible to the community of Surveillance Studies has had it pleasures and rewards, and indeed has produced results which have surprised me, much has been lost.

In particular, this contortion to legibility seems to have wrung the fun from the event, and this seems a real dishonoring of its truth. It was, intellectually and physically, a fabulously inventive, creative, and boundary-pushing two weeks. And we produced a great show. People loved it. Theatre students liked it. Academics liked it. Drama profs who specialize in collective creation thought we'd done a great job. Spouses had a blast. The tests and spectacles worked on enough levels that everyone was able to read something into them. Neta and Elyse's dancer piece, for example, was about art, disciplined instruction, disciplined bodies, torture, self-criticism/self-perception, endurance, voyeurism, cruelty, beauty. There were lots of way in, and the audience read the piece in as many ways.

But I am not sure how to fix that joy and fascination and circulate it within the academy. We did no preor post-tests on audience reception. My assertions - that it was a great show, that the audience loved it, that it was a joy-are simply anecdotal, subjective, and perhaps self-serving. Even with that admission, I'm very aware of the care I must take to refer to that joy in ways that are not "too informal and personal" and that comport with "[this journal's] editorial requirements and ... style," as the review editors put to me.

I hope that this article does something to stoke a conversation about method and findings and joy and the ineffable that I would very much like to remain a part of. I left this project more convinced than I entered it that this kind of theatrical construction is an extremely powerful research method. In two weeks, in our first effort, we had constructed an extremely nuanced, complex, evocative and vital model of life within actuarial surveillance. We were knocking at the back door of surveillance theory, ready to walk in and rearrange the furniture. I hope that its circumspect circulation within the field of Surveillance Studies enlists collaborators, critics, and funders to future iterations and elaborations of these techniques.

\section{Acknowledgements}

This research was supported by Social Science and Humanities Research Council of Canada grant \#72035904.

\section{References}

Arsem, Marilyn. 2009. Performed Research: Audience as Investigator. In Mapping Landscapes for Performance as Research: Scholarly Acts and Creative Cartographies, edited by Shannon Rose Riley and Lynette Hunter, 207 - 213. New York: Palgrave Macmillan.

Bagley, Carl. 2008. Educational Ethnography as Performance Art: Towards a Sensuous Feeling and Knowing. Qualitative Research 8(1): 53-72.

Bagley, Carl. 2009. The Ethnographer as Impresario-Joker in the (Re)presentation of Educational Research as Performance Art: Towards a Performance Ethic. Ethnography and Education 4(3): 284 - 300.

Boal, Augusto. 1985. Theatre of the Oppressed. Translated by Charles A. Leal \& Maria-Odilia Leal. New York: Theatre Communications Group.

Boal, Augusto. 1992. Games for Actors and Non-Actors. Translated by Adrian Jackson. New York: Routledge.

Butler, Judith. 1998. Imitation and Gender Insubordination. In The Critical Tradition: Classic Texts and Contemporary Trends, 2nd ed. Edited by David H. Richter, 1514-1525. New York: Bedford/St. Martin's. 
Campbell, John. 2005. Outing PlanetOut: Surveillance, Gay Marketing and Internet Affinity Portals. New Media and Society 7(5): 663-683.

Churchill, Caryl. 2013. Love and Information. New York: Theatre Communications Group

Clarke, Roger. 1988. Information Technology and Dataveillance. Communications of the ACM 31(5): 498-512

Conquergood, Dwight. 2002. Performance Studies: Interventions and Radical Research. TDR 46(2): 145-156.

Conquergood, Dwight. 1985. Performing as a Moral Act: Ethical Dimensions of the Ethnography of Performance. Literature in Performance 5(2): 1-13.

Conrad, Diane. 2004. Exploring Risky Youth Experiences: Popular Theatre as a Participatory, Performative Research Method. International Journal of Qualitative Methods 3(1): 12-25.

Denzin, Norman K. 2003. Performance Ethnography: Critical Pedagogy and the Politics of Culture. Thousand Oaks, CA: Sage Publications.

Fabian, Johannes. 1990. Power and Performance: Ethnographic Explorations through Proverbial Wisdom and Theatre in Shaba, Zaire. Madison: The University of Wisconsin Press.

Foucault, Michel. 1977. Discipline and Punish: The Birth of the Prison. Translated by Alan Sheridan. New York: Pantheon Books.

Giddens, Anthony. 1984. The Constitution of Society: Outline of the Theory of Structuration. Berkeley, CA: University of California Press.

Goffman, Erving. 1959. The Presentation of Self in Everyday Life. New York: Doubleday.

Grimmelmann, James. 2009. Saving Facebook. Iowa Law Review 94: 1137-1206.

Hunter, Lynette. 2009. Theory/Practice as Research: Explorations, Questions, and Suggestions. In Mapping Landscapes for Performance as Research: Scholarly Acts and Creative Cartographies, edited by Shannon Rose Riley and Lynette Hunter, 231-236. New York: Palgrave Macmillan.

Lemke, Jay. 2008. Identity, Development, and Desire: Critical Questions. In Identity Trouble, edited by Carmen Rosa CaldaCoulthard and Rick Iedema, 17-42. New York: Palgrave Macmillan.

Levin, Thomas, Ursula Frohne, and Peter Weibel, eds. 2002. Ctrl [space]: Rhetorics of Surveillance from Bentham to Big Brother. Cambridge, MA: MIT Press.

Luker, Kristin. 2010. Salsa Dancing into the Social Sciences. Cambridge, MA: Harvard University Press.

McGrath, John. 2004. Loving Big Brother: Performance, Privacy, and Surveillance Space. London: Routledge.

McGrath, John. 2012. Performing Surveillance. In Routledge Handbook of Surveillance Studies, edited by Kirstie S. Ball, Kevin D. Haggerty, and David Lyon, 83-90. London: Routledge.

Phillips, David J. 2005. From Privacy to Visibility: Context, Identity, and Power in Ubiquitous Computing Environments. Social Text 23(2): 95-108.

Phillips, David J. 2009. Ubiquitous Computing, Spatiality, and the Construction of Identity: Directions for Policy Response. In Privacy, Identity and Anonymity in a Network World: Lessons from the ID Trail, edited by Ian Kerr, Valerie Steeves and Carole Lucock, 303-318. New York: Oxford University Press.

Phillips, David J. 2011a. Identity and Surveillance Play in Hybrid Space. In Online Territories: Mediated Practice and Social Space, edited by Miyase Christensen, Andre Jansson and Christian Christensen, 171-184. New York: Peter Lang.

Phillips, David J. 2011b. Erotics and Repression in Stranger Chat Sites. Feb 18. In Media Res: A MediaCommons Project. Available at: http://mediacommons.futureofthebook.org/imr/2011/02/18/erotics-and-repression-stranger-chat-sites

Spatz, Ben. 2011. Practice as Research: Foundations for a Community of Knowledge. Dance Research Journal 43(1): 48-57.

Steeves, Valerie. 2006. It's Not Child's Play: The Online Invasion of Children's Privacy. University of Ottawa Law \& Technology Journal 3: 169-188.

Tomasula, Steve. 2000/2001. C-U See-Me. Iowa Review 30(3): 3-28. 


\section{Appendix: PHOTOS}

\section{Progress, from the sublime to the mundane}
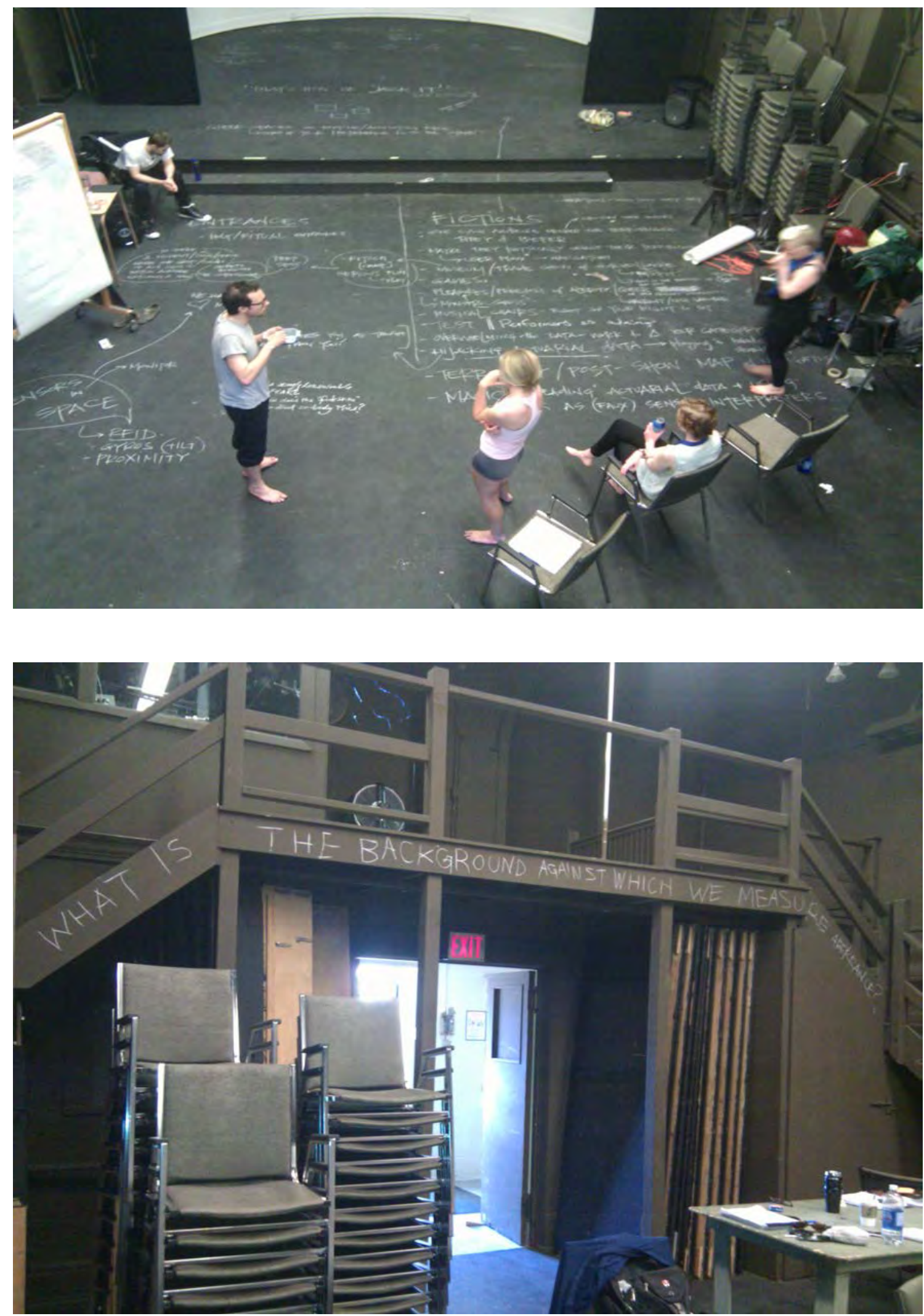

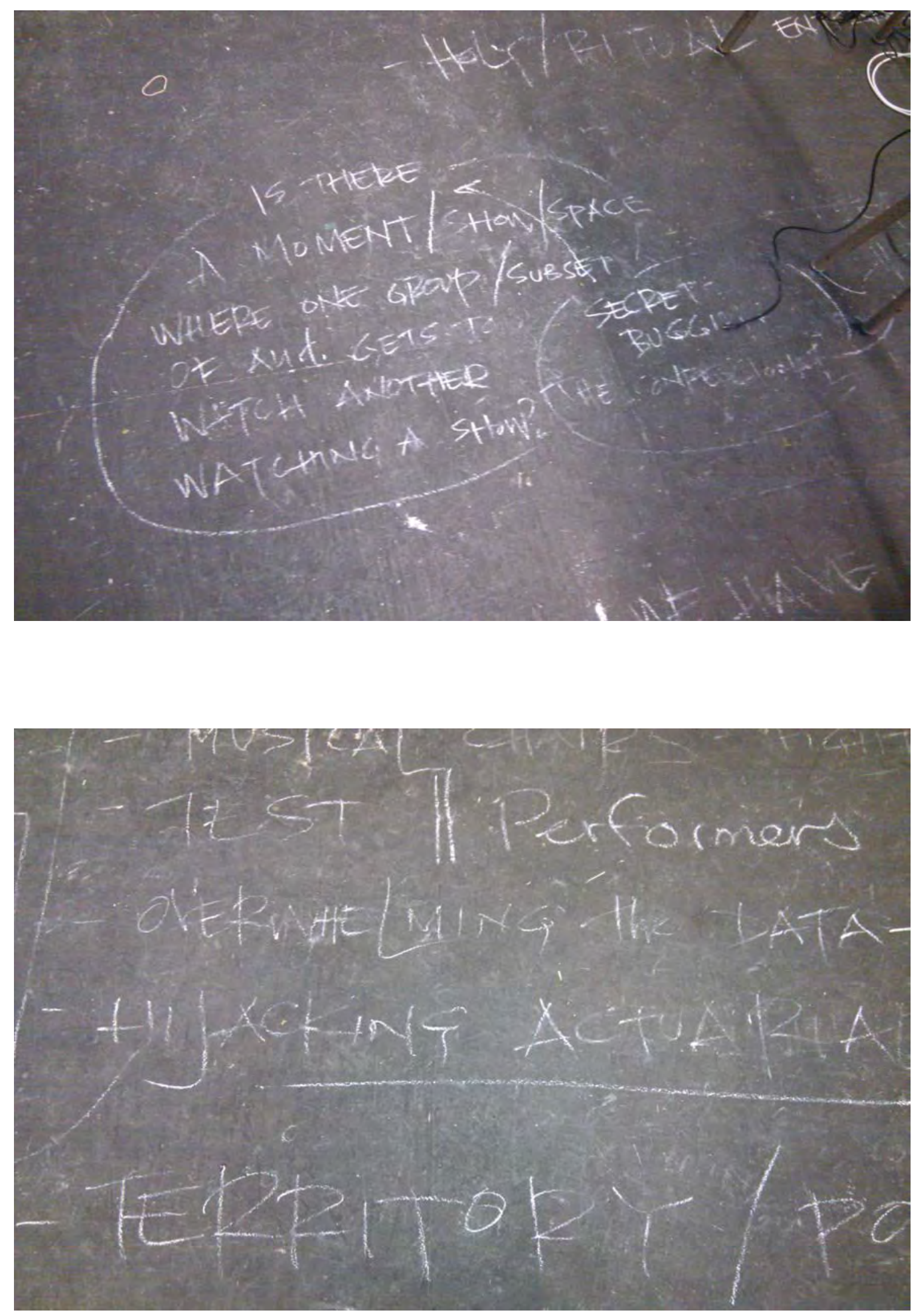

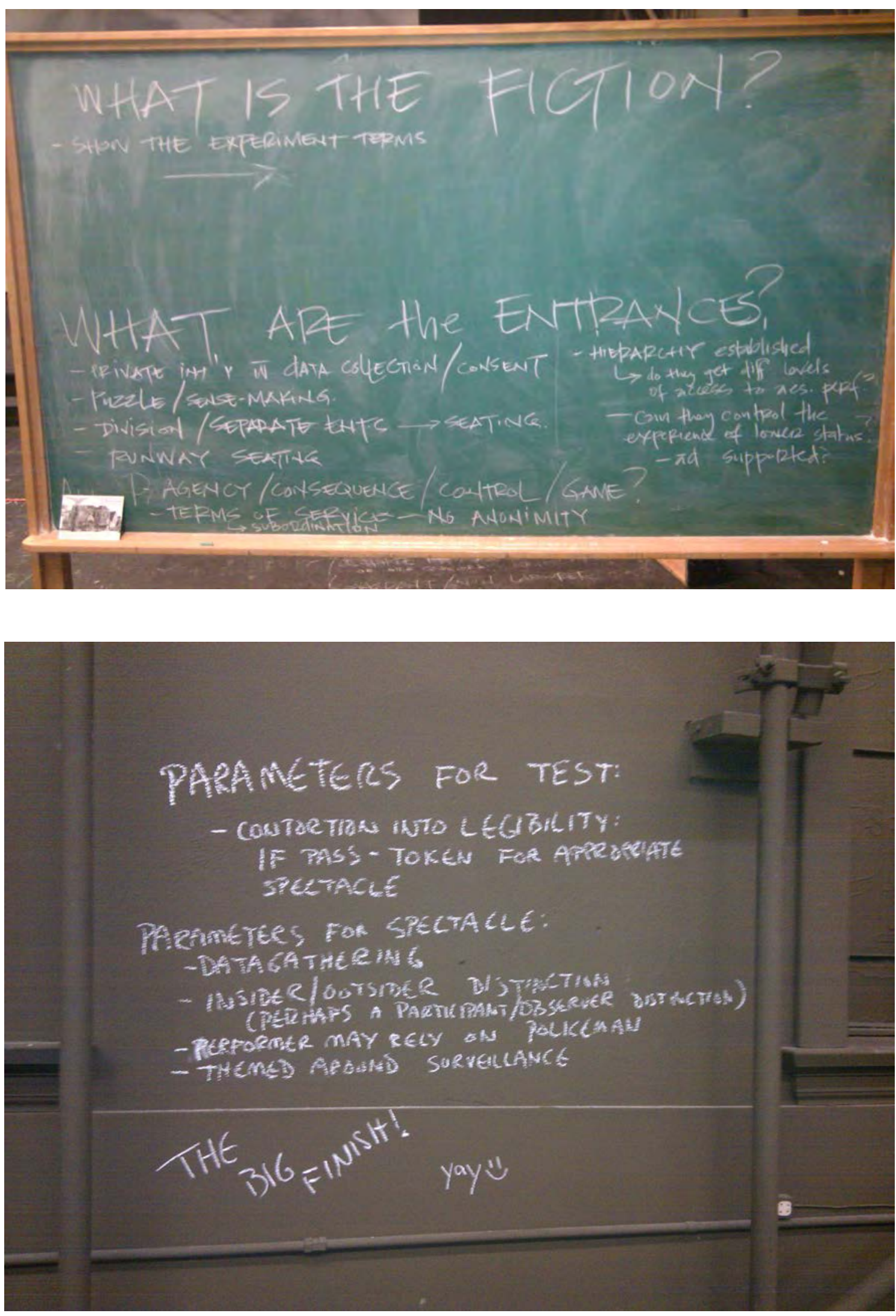


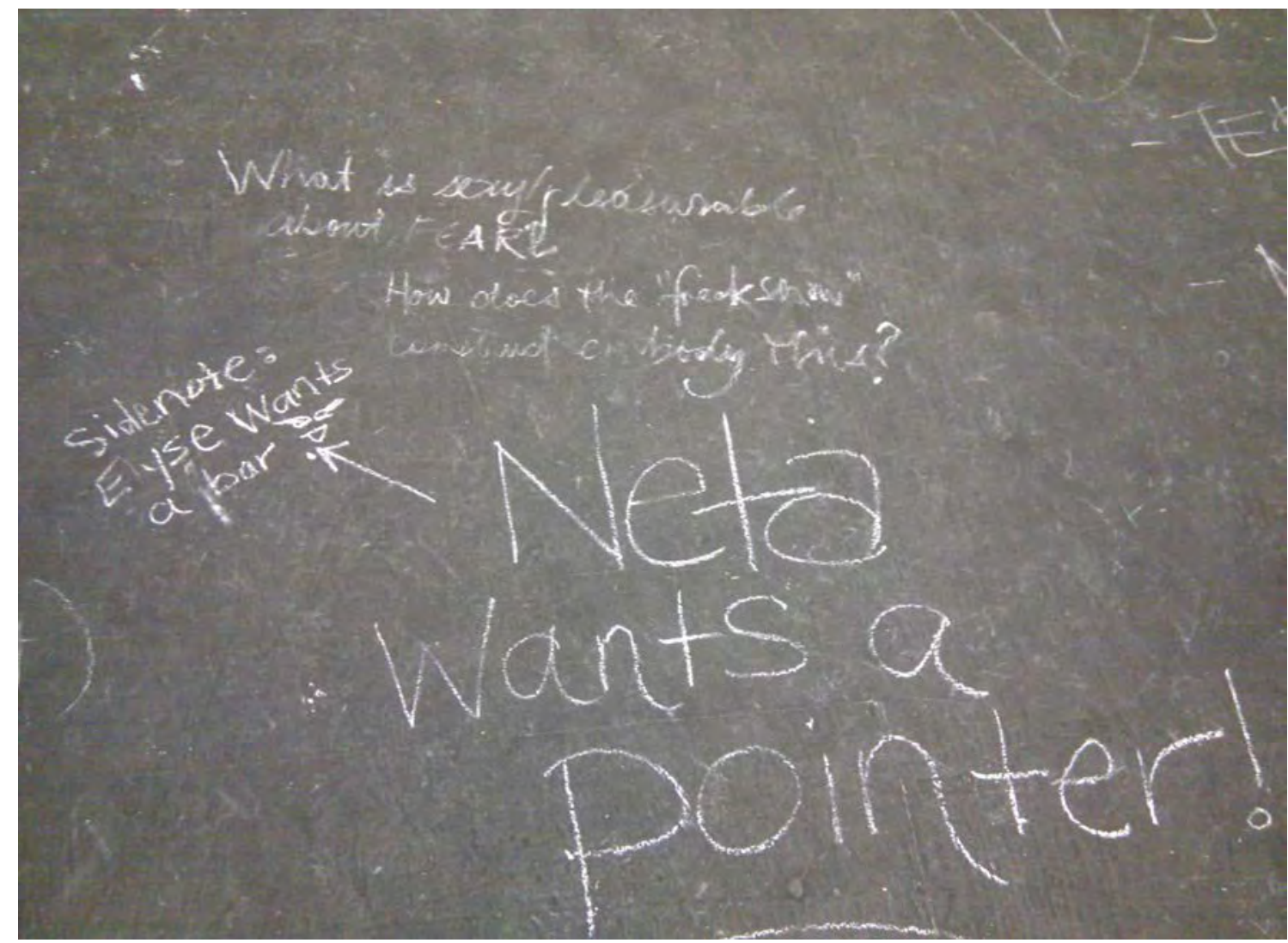

Enrolling the audience

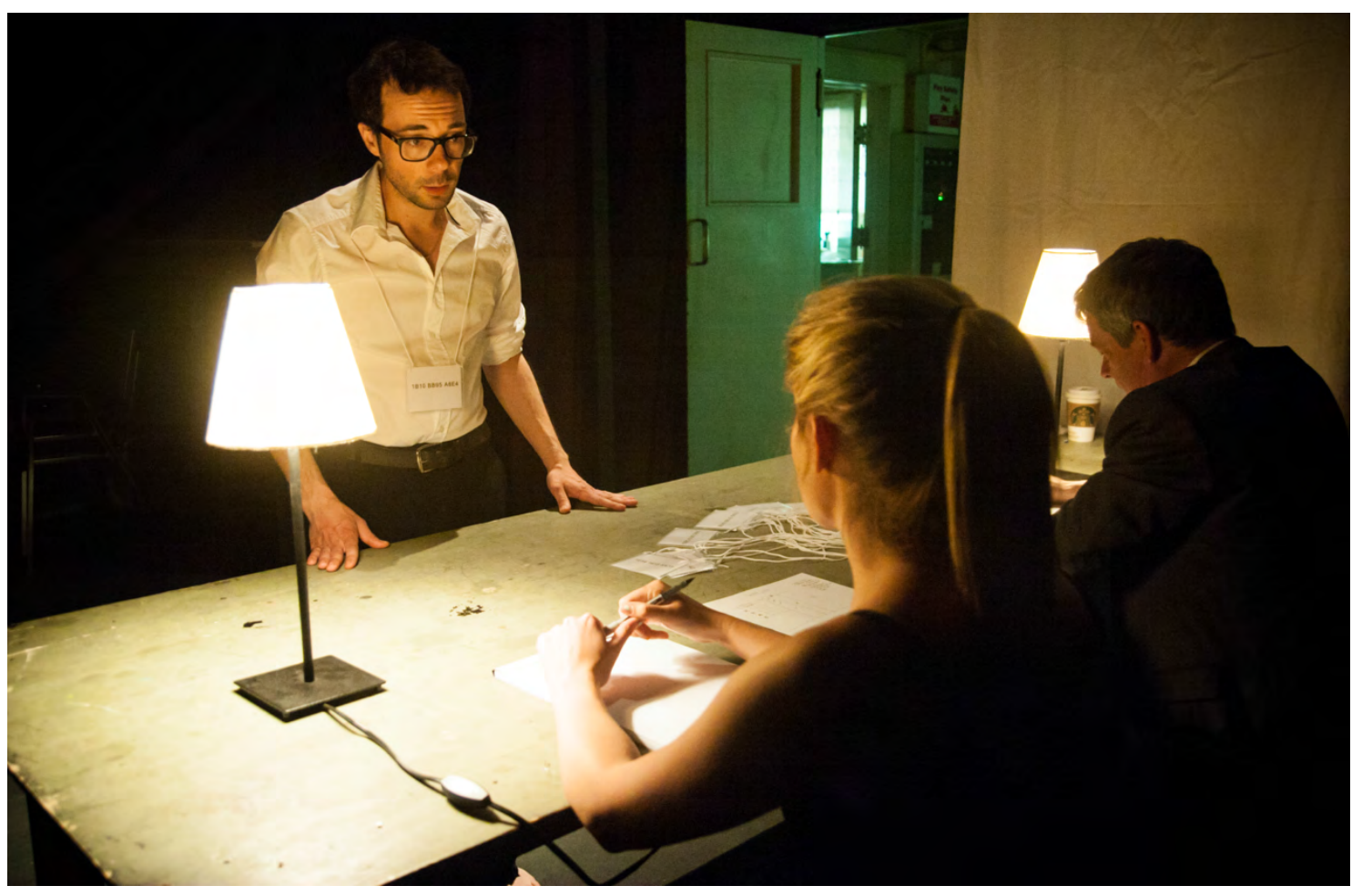




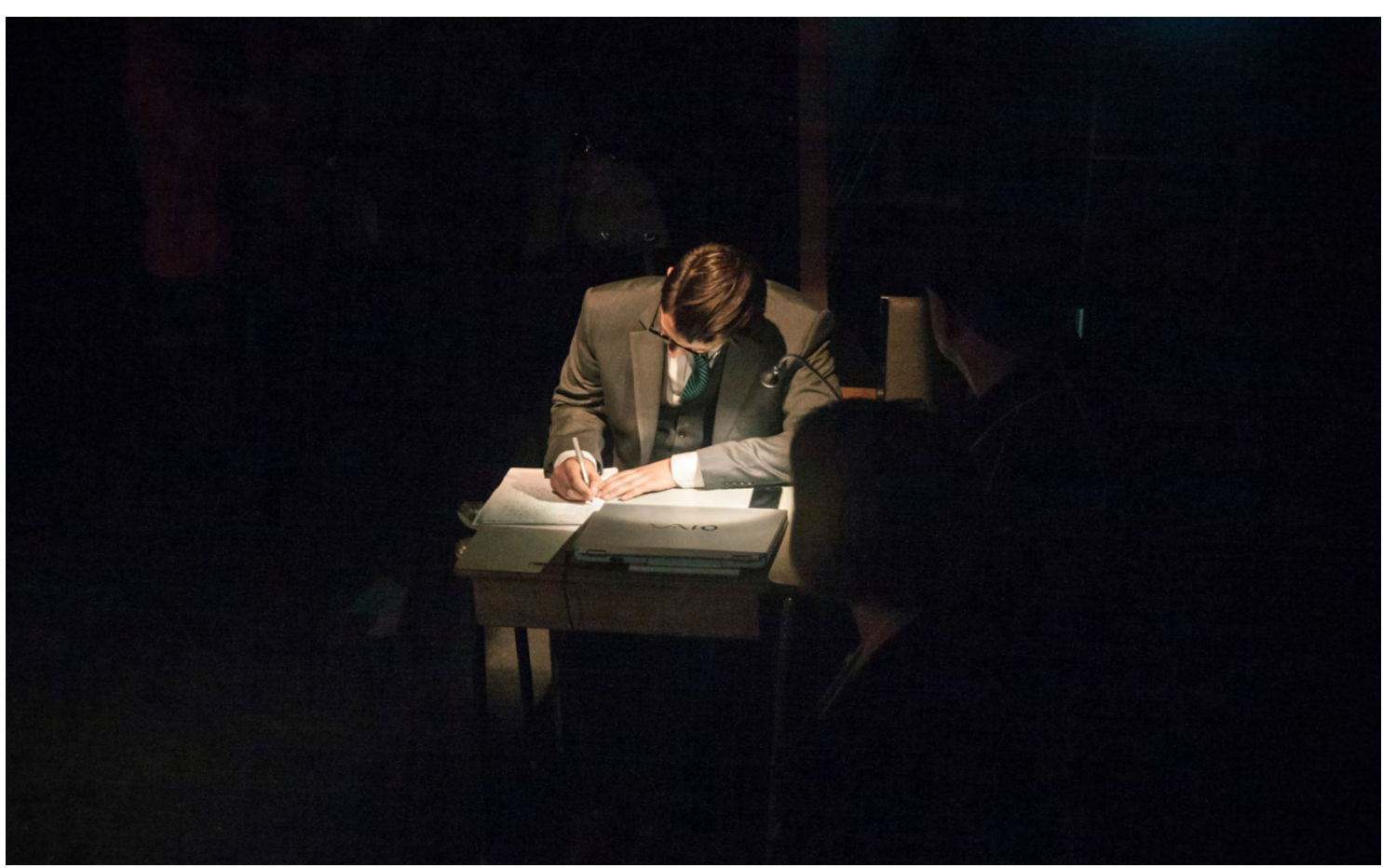

Neta and the excellent history of scientific legibility

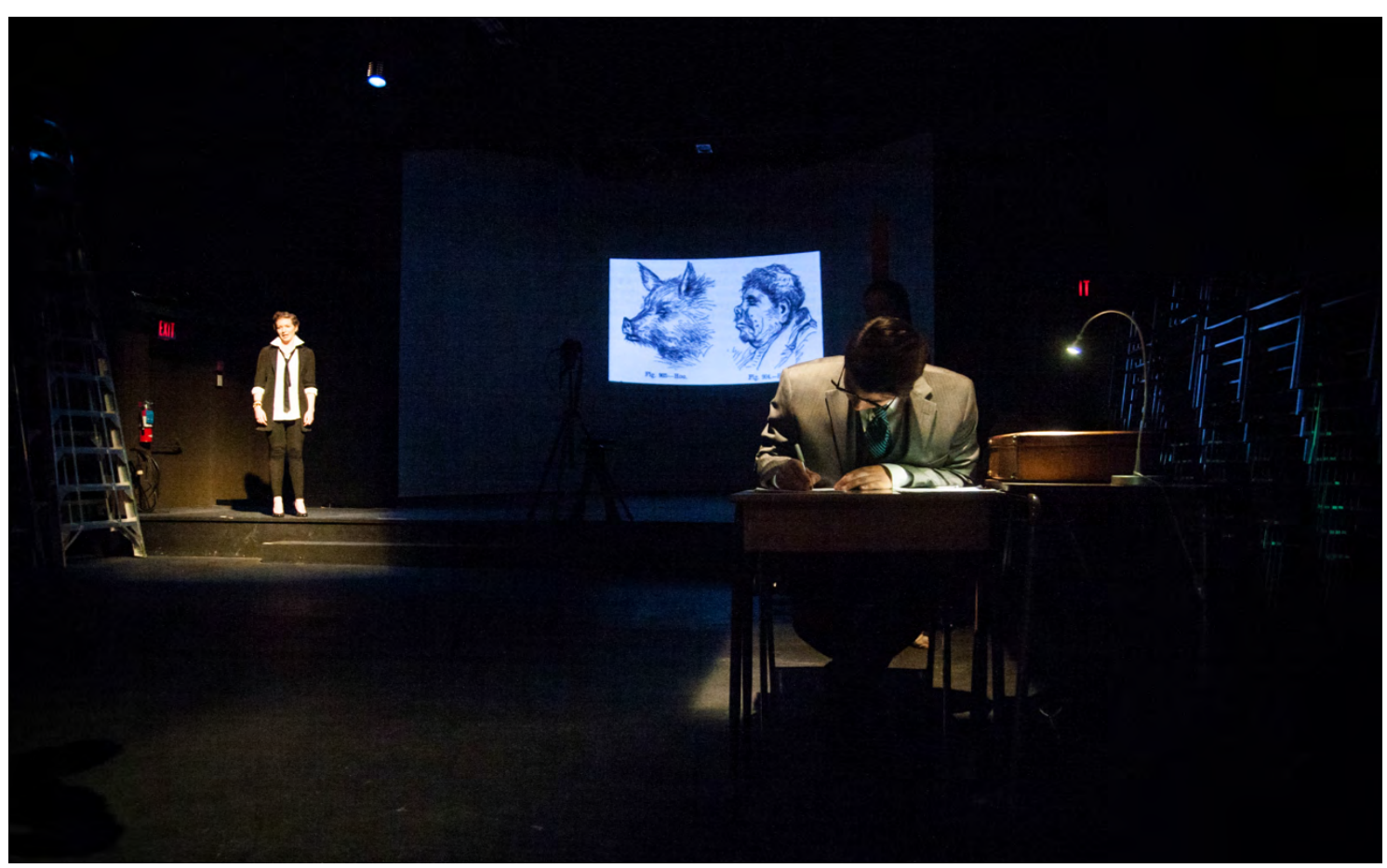


Neta administering the psychographic test

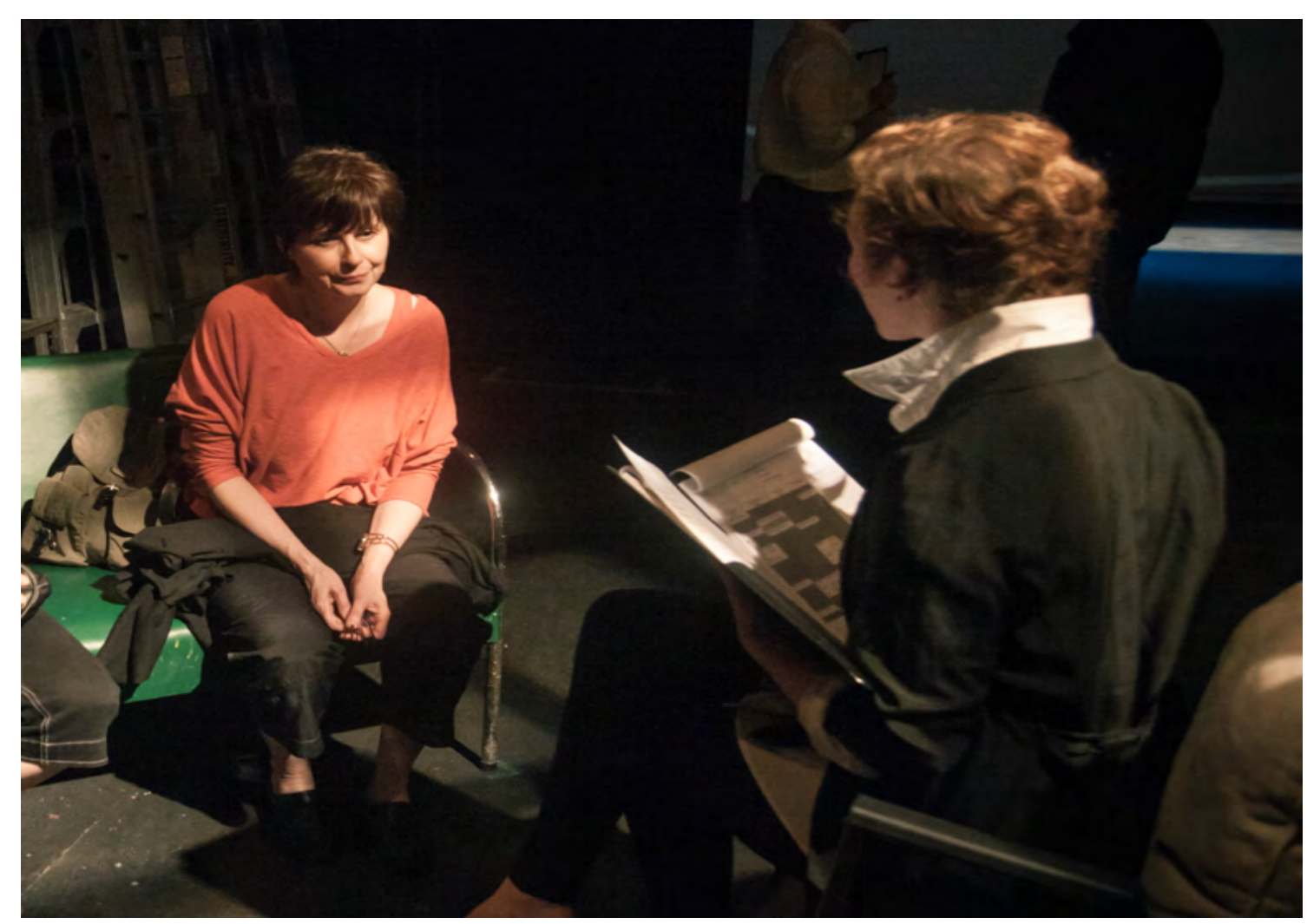

The jitter monitor

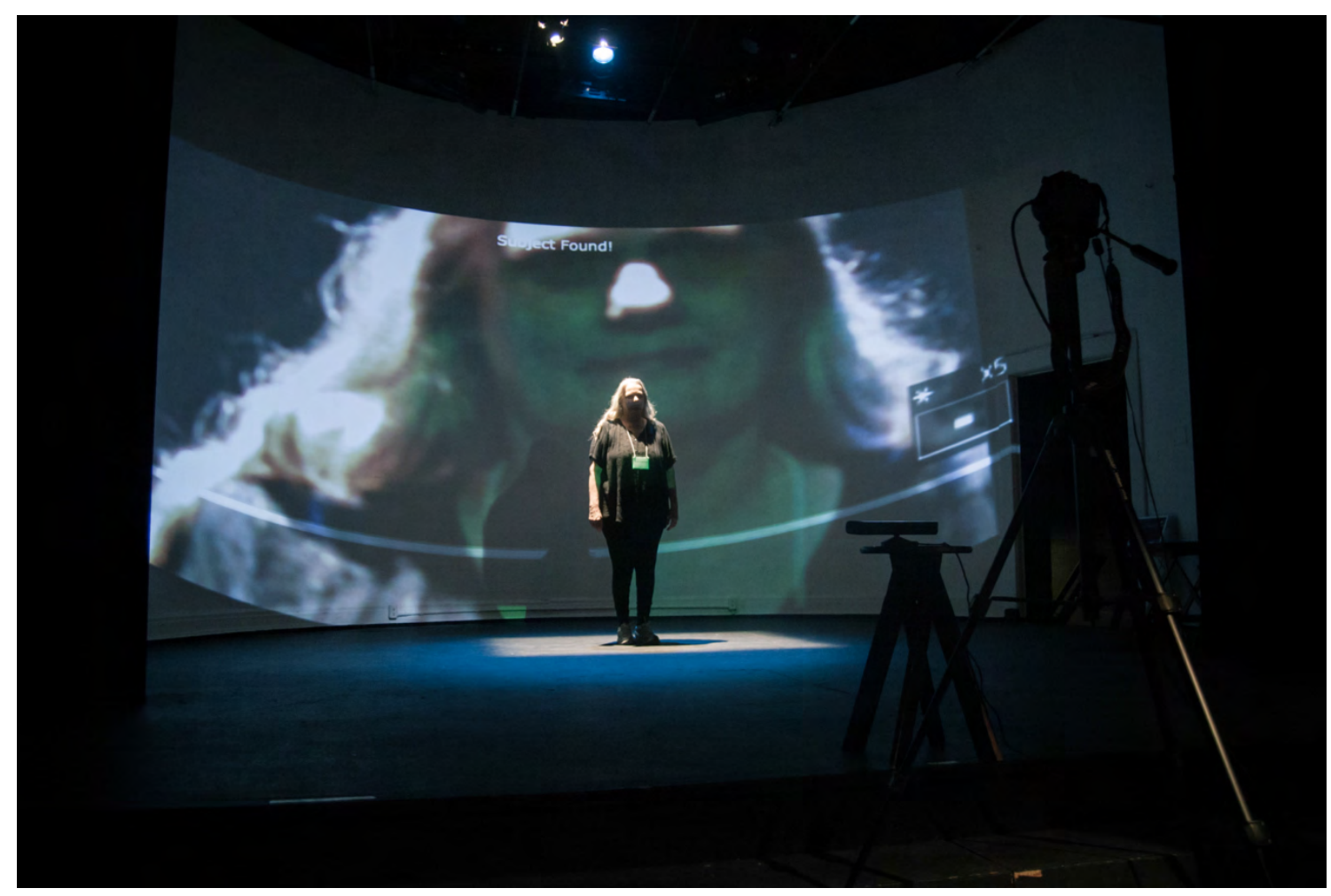


The disciplined dancer

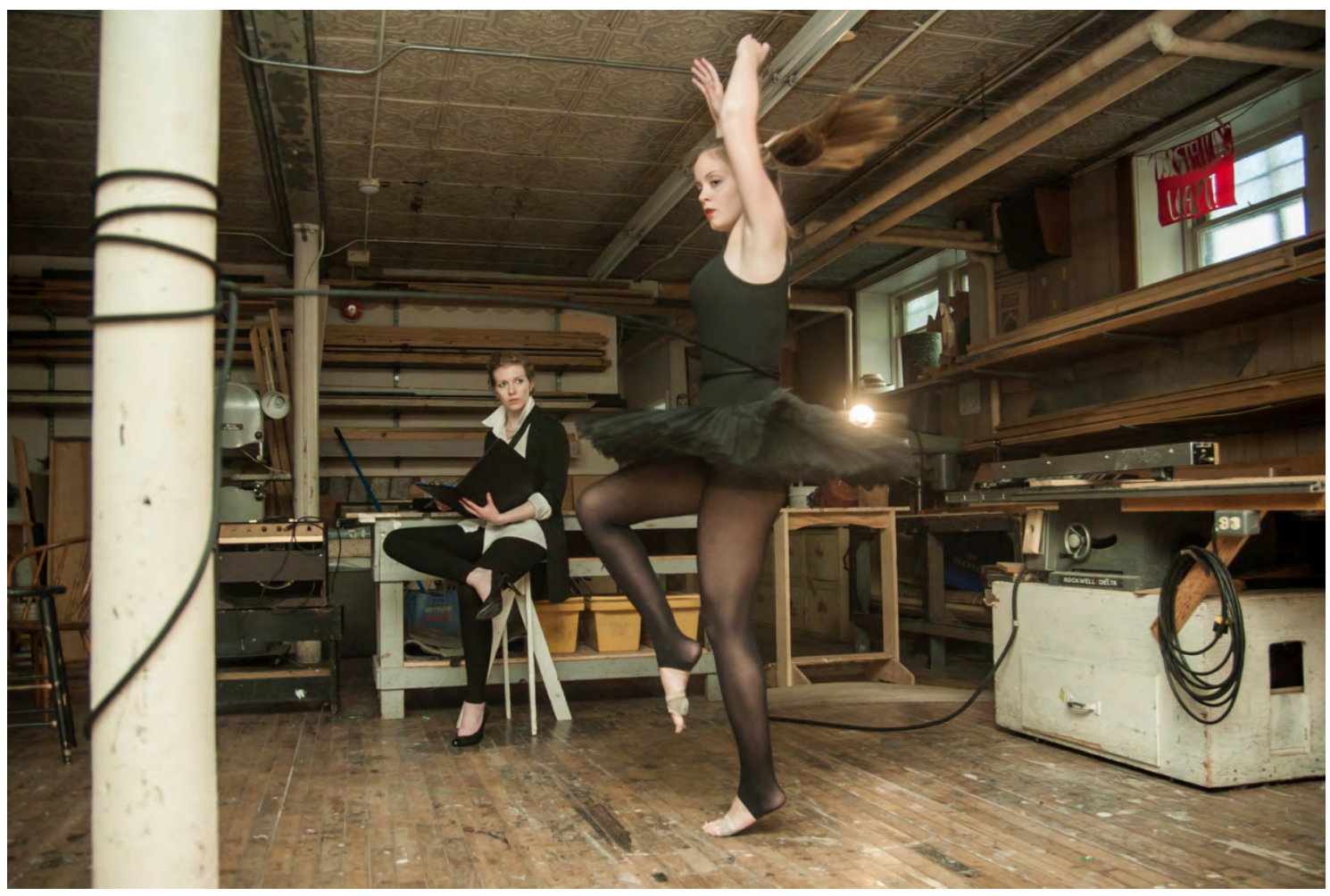

The blind painter

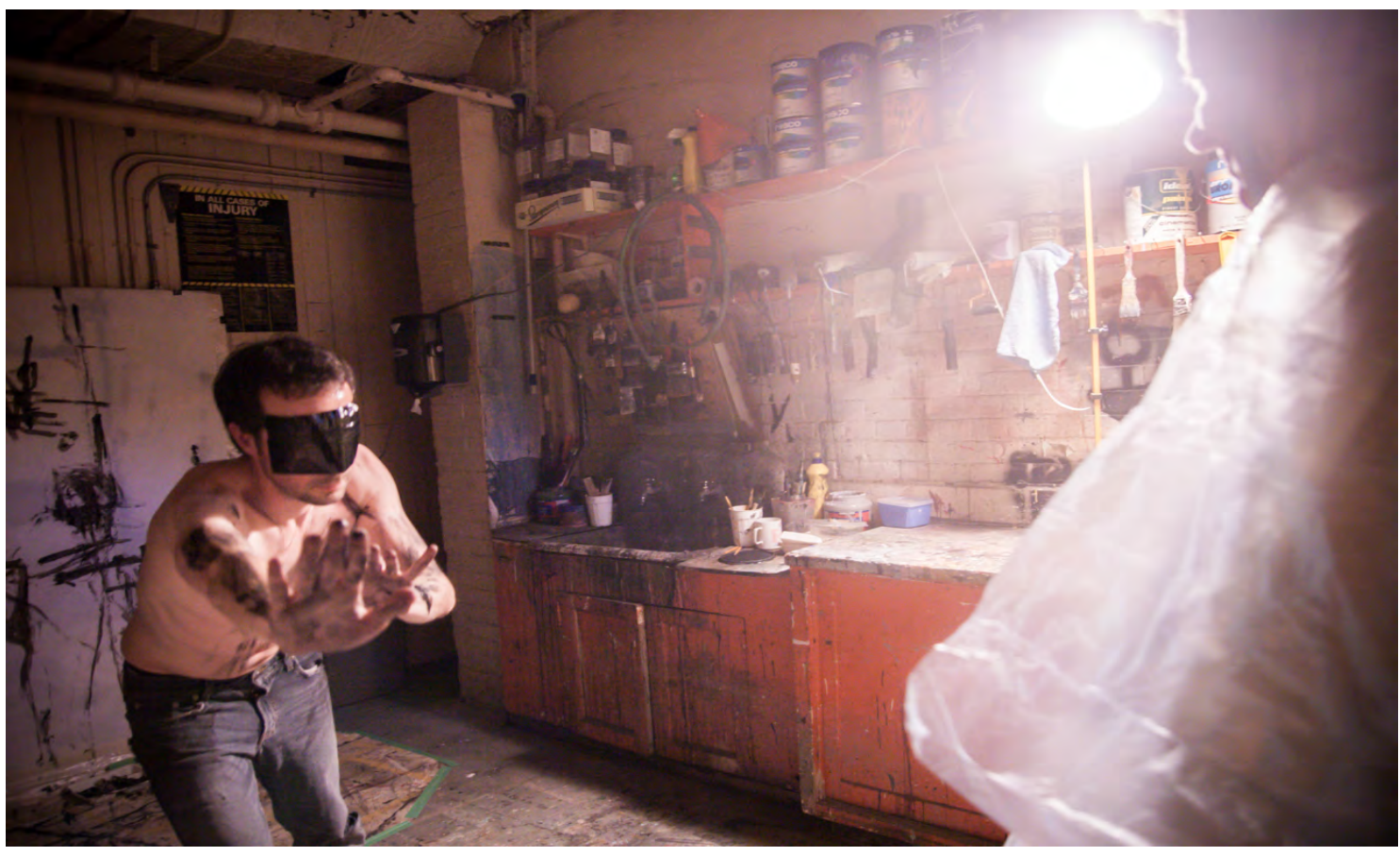


The Satisfaction of Shameful Desires

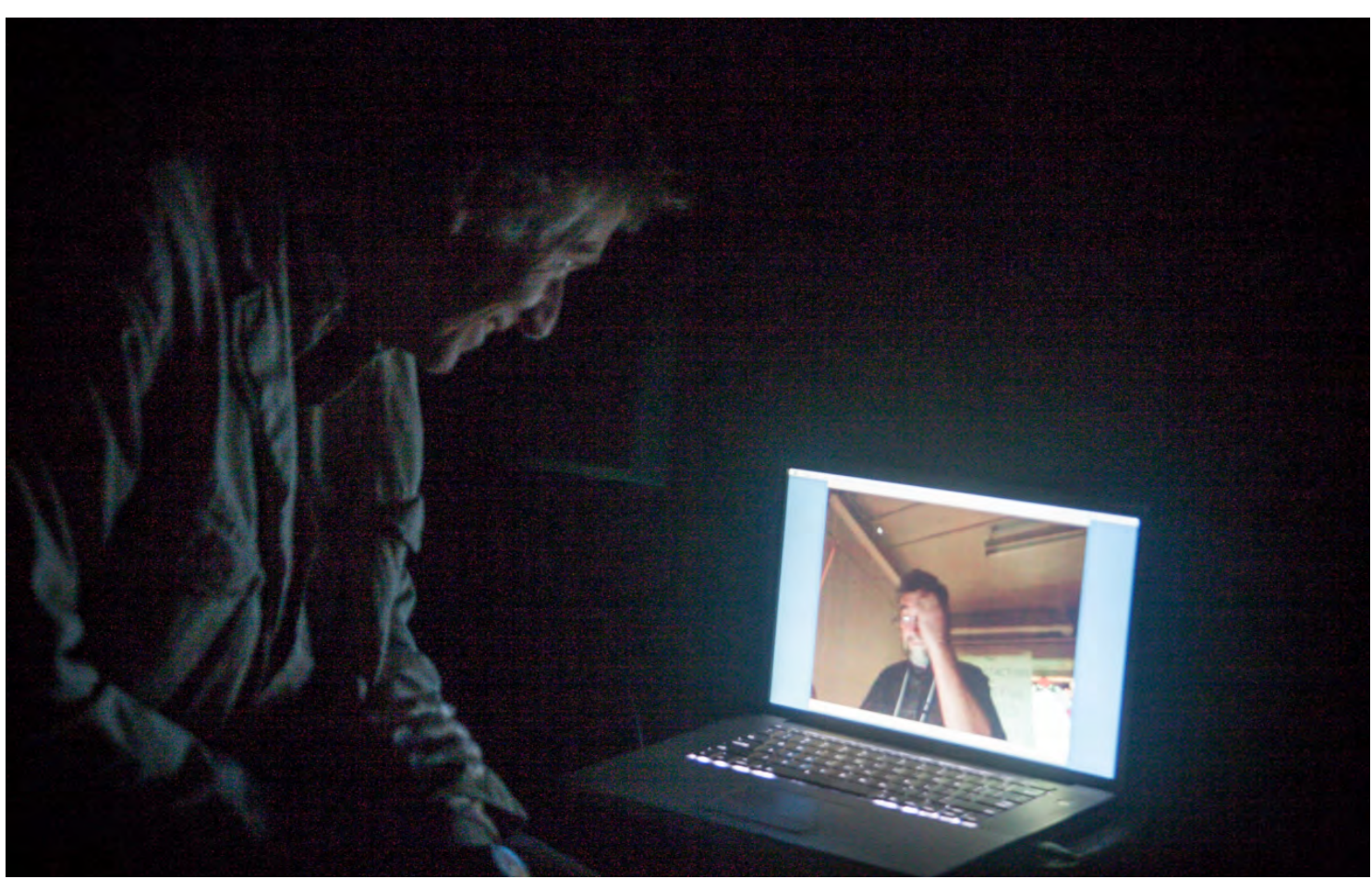

The Big Finish

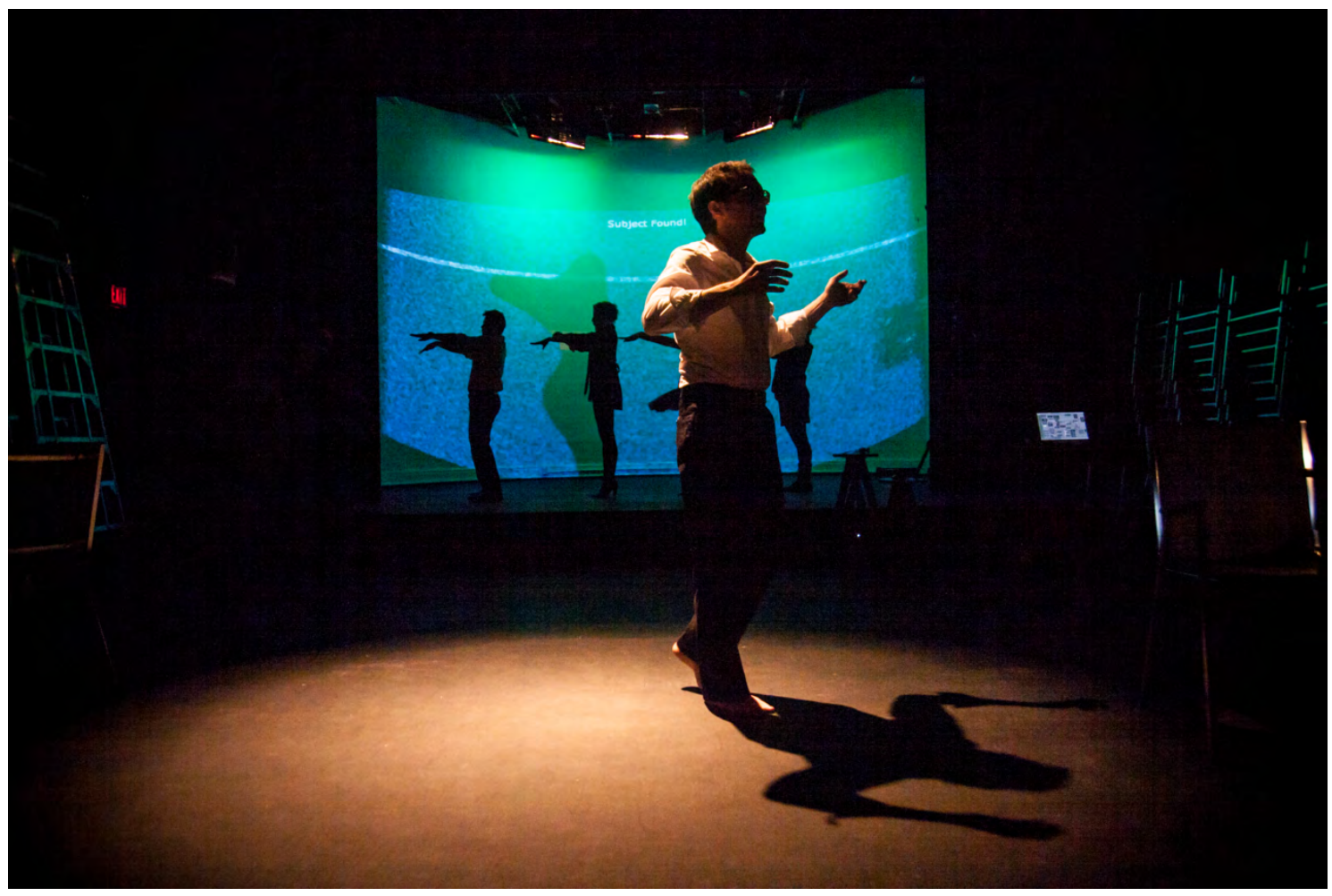

